\title{
Clinical Reasoning: Sudden hearing loss with vertigo in a 42-year-old woman
}

Jeong-Yoon Choi, MD, PhD, Hyo-Jung Kim, PhD, and Ji-Soo Kim, MD, PhD

Neurology ${ }^{\circledR}$ 2020;94:1042-1047. doi:10.1212/WNL.0000000000009591
Correspondence

Dr. Kim

jisookim@snu.ac.kr

\section{Section 1}

A 42-year-old previously healthy woman developed sudden right hearing loss, vertigo, and nausea. She had a dull and compressing sensation in the right ear but denied any significant headache or neck pain. She had no medical history including vascular risk factors and neuro-otologic disorders and denied a recent history of head and neck trauma. Review of systems was unremarkable. Neurologic examination showed a small spontaneous downbeat nystagmus only in darkness without visual fixation. The downbeat nystagmus increased after horizontal head-shaking and in the straight-head hanging position. There was neither gaze-evoked nystagmus nor skew deviation. Bedside horizontal head impulse tests (HITs) and other neurologic examinations were also normal. Pure tone audiometry documented a profound sensorineural hearing loss (SNHL) in the right ear with a pure tone average at $100 \mathrm{~dB}$ (figure, A). Video-HITs showed normal head impulse gains for all 6 semicircular canals (SCCs) but small covert saccades for right posterior SCC. The results of bithermal caloric tests, cervical and ocular vestibular-evoked myogenic potentials, and measurements of subjective visual vertical were normal.

\section{Question for consideration:}

1. Where does SNHL localize?

\section{GO TO SECTION 2}


Figure Patient findings

A

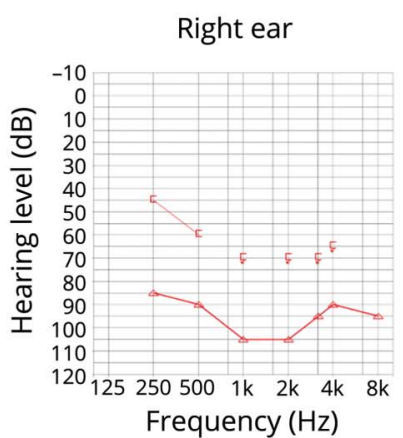

C
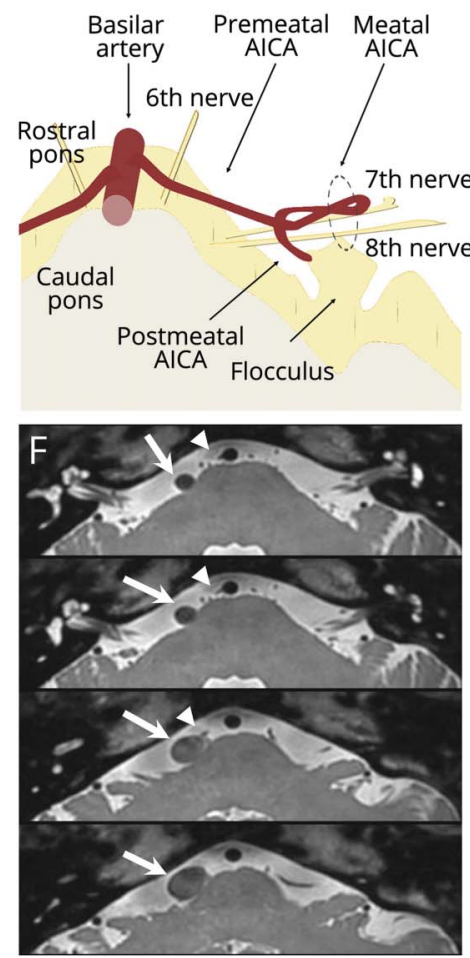

Left ear
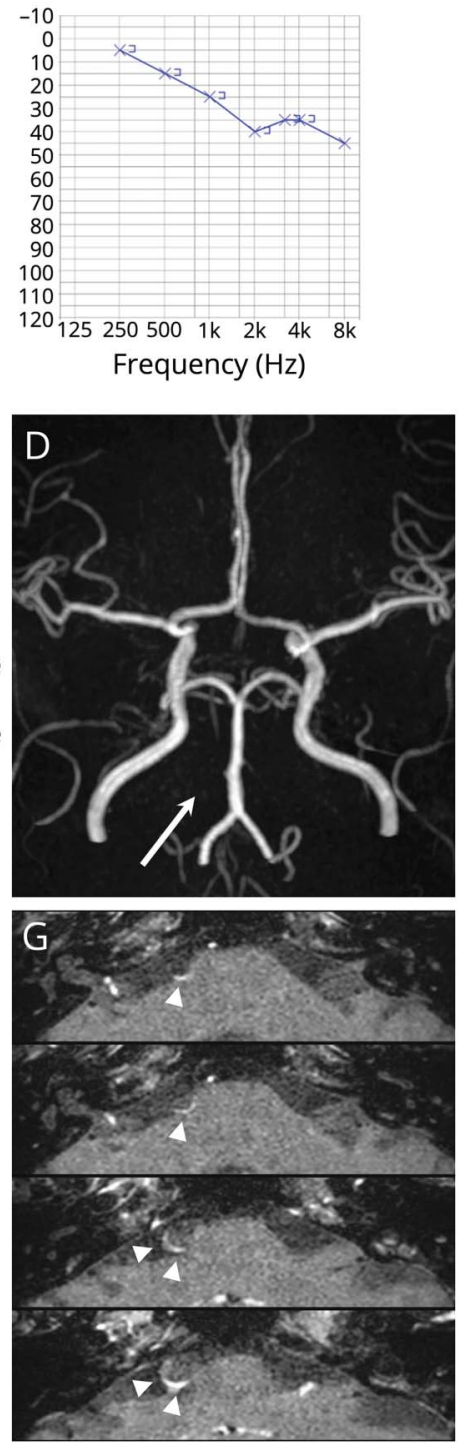
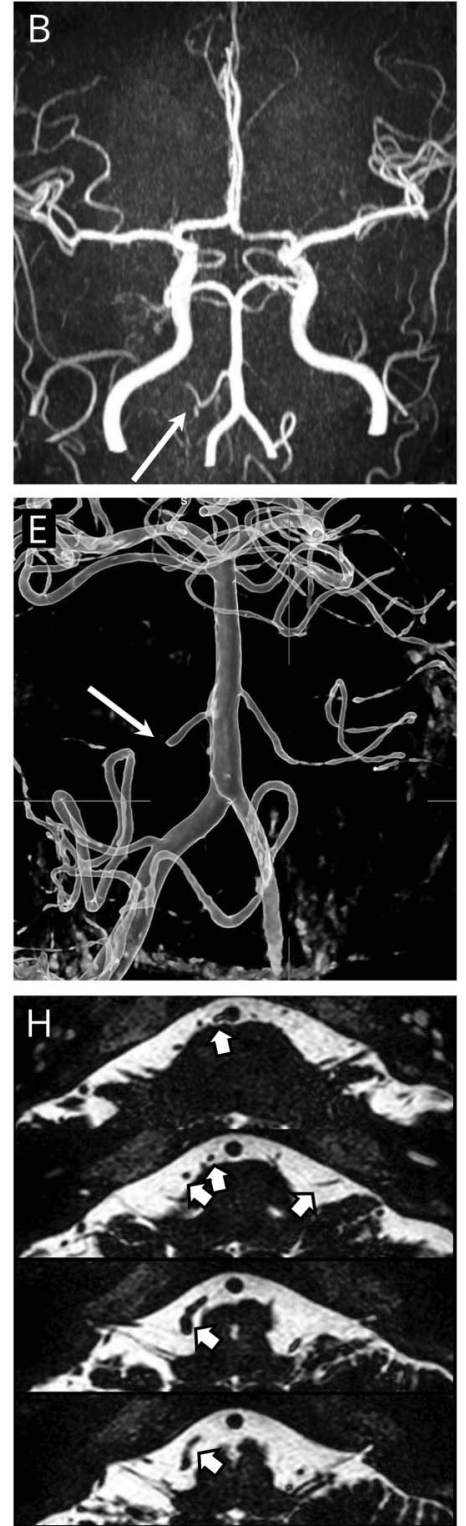

(A) Pure tone audiometry shows a profound hearing loss in the right ear at initial presentation. (B) The initial time of flight (TOF) angiography shows a rather prominent anterior inferior cerebellar artery (AICA) (arrows). (C) Schematic illustration of the relationship between the AICA and the facial and vestibulocochlear nerves in the brainstem and cerebellopontine cistern. (D) In the TOF angiography during the second event, right AICA was cut off at the proximal portion (arrow). (E) Digital subtraction angiography clearly demonstrates an occlusion of the right AICA at the premeatal segment but normal left AICA. (F, G) High-resolution vessel wall imaging shows a $1 \mathrm{~cm}$, oval, $T 2$ hypointense mass in the right cerebellopontine cistern ( $F$, arrow) that arises from right AICA ( $F$, arrowhead), suggestive of AICA aneurysm. In addition, there is an eccentric hyperintensity in the mass (G, arrowhead), consistent with a dissecting aneurysm. $(\mathrm{H})$ Review of the initial MRIs reveals that the distal segment of AICA is dilated vs the proximal segment and the contralateral AICA (arrow). 


\section{Section 2}

Sudden SNHL can result from any lesions involving the auditory projection, but lesion location can be inferred from associated vertigo and nystagmus. Although benign paroxysmal positional vertigo occasionally occurs in association with sudden SNHL, the downbeat nystagmus in the head upright position, the nature of spontaneous vertigo, and the absence of previous episodes contradict benign paroxysmal positional vertigo. ${ }^{1,2}$ Primary downbeat nystagmus can develop in lesions involving the posterior SCC projection or inferior cerebellum. ${ }^{2}$ Small covert saccades during HITs for right posterior SCC in the absence of any central neurologic signs favor a lesion involving the posterior SCC or the inferior vestibular nerve. ${ }^{2}$ The anatomical proximity between the cochlea and posterior SCC and between the cochlear and inferior vestibular nerves may explain the clinical manifestation. ${ }^{2}$ However, downbeat nystagmus is more commonly observed in inferior cerebellar lesions that may cause vertigo without other central neurologic signs. ${ }^{2}$ Therefore, sudden SNHL with vertigo can be localized from the inner ear to the pontocerebellar region.

\section{Questions for consideration:}

1. What are the causes of sudden SNHL with or without vertigo?

2. Should we scan her brain?

3. What is the most plausible cause of sudden SNHL and vertigo in this patient?

GO TO SECTION 3 


\section{Section 3}

Sudden SNHL with vertigo is mostly attributed to vascular, traumatic, and inflammatory disorders (table e-1, doi.org/ $10.5061 /$ dryad.sf $7 \mathrm{~m} 0 \mathrm{cg} 1 \mathrm{v}){ }^{3}$ Thus, imaging of the brain, intracranial and extracranial vessels, labyrinth, and internal auditory canal may be required. In this patient, findings of gadolinium-enhanced brain MRI were normal and time of flight (TOF) and contrast magnetic resonance angiography (MRA) well-visualized right anterior inferior cerebellar artery (AICA) (figure, B). Serologic tests for autoimmune or other systemic disorders were unremarkable. The patient had a presumptive diagnosis of idiopathic neurolabyrinthitis based on the normal MRIs and MRA, young age, absence of known vascular risk factors, and no recent history of neck or head trauma.
Vertigo and downbeat nystagmus disappeared within 1 week, but the hearing loss remained unchanged over the following 3 months despite oral and intratympanic steroid administration. One year later, the patient revisited the emergency department with a newly developed right facial palsy following transient spontaneous vertigo for about 5 minutes. The patient could not wrinkle her right forehead and reported pain in the right retroauricular area along with dryness of the right eye. The hearing loss in the right ear remained unchanged. Other findings of neurologic and neuro-otologic examination were normal.

\section{Questions for consideration:}

1. How can we explain these sequential neurologic presentations?

2. Should we rescan her brain?

3. What is the diagnosis for this patient? 


\section{Section 4}

The peripheral type of facial palsy alluded that the lesion was located distal to the facial nucleus. ${ }^{4}$ The preceding vertigo without other neurologic symptoms and signs further localizes the lesion in the cerebellopontine angle and internal auditory canal where the facial and vestibular nerves run together (figure, C). ${ }^{4}$ Given the previous attack of sudden SNHL with vertigo, the patient's symptoms may be ascribed to isolated thromboembolism involving the arteries and nerves in the internal auditory canal that might have been missed during the prior evaluation, or recurrent inflammation from viral reactivation or autoimmune disorders.

Follow-up diffusion-weighted MRIs were normal, but perfusion was delayed over the right AICA territory in the time to peak map, which implies concomitant ischemia of the inner ear supplied by the internal auditory artery, a terminal branch of the AICA. The TOF and contrast MRA showed a disappearance of the wellvisualized right AICA on the previous MRA (figure, D). Catheter angiography confirmed a complete occlusion of the proximal segment of right AICA (figure, E). High-resolution vessel wall imaging showed a $1-\mathrm{cm}$ oval mass in the right cerebellopontine cistern where the AICA branches the internal auditory artery (figure, $\mathrm{F}$ and G). The mass was originated from the AICA and was characterized by heterogeneous $\mathrm{T} 2$ hypointensity with eccentric $\mathrm{T} 1$ contrast enhancement, indicating a dissecting AICA aneurysm. ${ }^{5}$ A review of the previous MRIs revealed that the distal segment of the right AICA was dilated more than the proximal and contralateral segments (figure, $\mathrm{H}$ ), which is suggestive of an arterial dissection. ${ }^{5}$ Repeated investigation on autoimmune and rheumatologic disorders was again unrevealing. All these findings indicated serial developments of spontaneous AICA dissection, aneurysmal formation, and finally ischemia of the cochleovestibular and facial nerves due to thrombosis of the aneurysm.

Given the potential risk of subarachnoid hemorrhage that could occur during recanalization, ${ }^{6}$ antiplatelets and anticoagulants were not administered. The patient developed no additional neurologic symptoms and signs, and the occluded dissecting aneurysm remained stable on follow-up MRA 12 months later. The facial palsy resolved, but the hearing loss remained without improvement.

\section{Discussion}

This is the first documentation of AICA ischemia/infarction due to thrombotic occlusion of the dissecting aneurysm. This study highlights the possible linkage between one of the common neurologic symptoms, sudden SNHL with vertigo, and life-threatening cerebellar artery dissection. Although cerebellar artery dissection is extremely rare and challenging to diagnose, ${ }^{6}$ it should be recognized as a cause for sudden SNHL with or without vertigo.

In this patient, the dilation of right distal AICA segment on the initial MRA was an early sign of dissection. ${ }^{5}$ Thus sudden
SNHL and vertigo at the initial presentation appeared to be due to distal embolization from the dissecting AICA at the proximal portion. The profound hearing loss with a poor response to systemic and intratympanic steroid administration is supportive of ischemic mechanism. ${ }^{3}$ Vertigo and peripheral facial palsy during the subsequent attack may be explained by ischemia/ infarction due to thrombotic or compressive occlusion of the vasa nervorum by the dissecting aneurysm.

Among the various etiologies of sudden SNHL with or without vertigo, vascular mechanisms have received little attention compared to neoplastic or inflammatory disorders. ${ }^{3}$ However, thromboembolic occlusion of the artery suppling the vestibulocochlear nerve or labyrinth, mostly AICA but rarely posterior inferior cerebellar artery, may give rise to isolated audiovestibulopathy. ${ }^{7}$ About $8 \%-30 \%$ of AICA strokes present with isolated audiovestibulopathy. ${ }^{7}$ Furthermore, the future stroke risk has been reported to be higher in patients with sudden SNHL than in a control group. ${ }^{8}$ Given its potentially grave prognosis, isolated audiovestibulopathy from inner ear ischemia should be searched carefully. MRIs are limited in assessing labyrinthine infarctions. ${ }^{9}$ Noninvasive techniques, including MRI or CT angiography and high-resolution magnetic resonance vessel wall imaging, are imperfect in the diagnosis of small intracranial vascular pathologies, especially cerebellar artery. ${ }^{10}$ Therefore, contemplation of clinical manifestation and cardiovascular risks is essential for suspicion of vascular inner ear damage. Careful follow-up with multimodal imaging approach is required even when those at risk of cerebrovascular events present with isolated audiovestibulopathy and normal imaging initially. This report expands the causes of acute isolated audiovestibulopathy into proximal AICA dissection.

\section{Study funding}

This study was supported by the Basic Science Research Program through the National Research Foundation of Korea (NRF) funded by the Ministry of Science and ICT (NRF2017R1C1B1008582).

\section{Disclosure}

J.-Y. Choi and H.-J. Kim report no relevant disclosures. J.-S. Kim serves as an Associate Editor of Frontiers in Neuro-Otology and on the editorial boards of the Journal of Clinical Neurology, Frontiers in Neuro-ophthalmology, Journal of Neuro-Ophthalmology, Journal of Vestibular Research, Journal of Neurology, and Medicine. Go to Neurology.org/ $\mathrm{N}$ for full disclosures.

Appendix Authors

\begin{tabular}{lll}
\hline Name & Location & Contribution \\
\hline $\begin{array}{l}\text { Jeong- } \\
\text { Yoon }\end{array}$ & $\begin{array}{l}\text { Department of Neurology, } \\
\text { Choi, MD, }\end{array}$ & $\begin{array}{l}\text { Acquired the data, } \\
\text { analyzed the data, drafted } \\
\text { the manuscript }\end{array}$ \\
PhD & College of Medicine; & \\
& Dizziness Center, Clinical & \\
& Neuroscience Center, & \\
& Department of Neurology, \\
& Seoul National University & \\
& Bundang Hospital, & \\
& Seongnam, Korea & \\
\hline
\end{tabular}


Appendix (continued)

\begin{tabular}{lll}
\hline Name & Location & Contribution \\
\hline $\begin{array}{l}\text { Hyo-Jung } \\
\text { Kim, PhD }\end{array}$ & $\begin{array}{l}\text { Research Administration } \\
\text { Team, Seoul National } \\
\text { University Bundang } \\
\text { Hospital, Seongnam, } \\
\text { Korea }\end{array}$ & $\begin{array}{l}\text { Acquired and analyzed the } \\
\text { data }\end{array}$ \\
& & \\
\hline Ji-Soo & Department of Neurology, & Conceptualized the study, \\
Kim, MD, & Seoul National University & $\begin{array}{l}\text { analyzed the data, revised } \\
\text { PhD }\end{array}$ \\
& College of Medicine; & \\
& Dizziness Center, & \\
& Clinical Neuroscience & \\
& Center, Department of & \\
& Neurology, Seoul & \\
& National University & \\
& Bundang Hospital, & \\
& Seongnam, Korea & \\
&
\end{tabular}

\section{References}

1. Kim JS, Zee DS. Clinical practice: benign paroxysmal positional vertigo. N Engl J Med 2014;370:1138-1147.

2. Leigh RJ, Zee DS. The Neurology of Eye Movements, 5th ed. New York: Oxford University Press; 2015.

3. Schreiber BE, Agrup C, Haskard DO, Luxon LM. Sudden sensorineural hearing loss. Lancet 2010;375:1203-1211.

4. Blumenfeld H. Neuroanatomy through Clinical Cases, 2nd ed. Sunderland: Sinauer Associates; 2010.

5. Choi YJ, Jung SC, Lee DH. Vessel wall imaging of the intracranial and cervical carotid arteries. J Stroke 2015;17:238-255.

6. Peluso JP, van Rooij WJ, Sluzewski M, Beute GN. Distal aneurysms of cerebellar arteries: incidence, clinical presentation, and outcome of endovascular parent vessel occlusion. AJNR Am J Neuroradiol 2007;28:1573-1578.

7. Lee H. Audiovestibular loss in anterior inferior cerebellar artery territory infarction: a window to early detection? J Neurol Sci 2012;313:153-159.

8. Lin HC, Chao PZ, Lee HC. Sudden sensorineural hearing loss increases the risk of stroke: a 5-year follow-up study. Stroke 2008;39:2744-2748.

9. Choi SY, Park JH, Kim HJ, Kim JS. Vestibulocochlear nerve infarction documented with diffusion-weighted MRI. J Neurol 2015;262:1363-1365.

10. Mohan IV. Current optimal assessment and management of carotid and vertebral spontaneous and traumatic dissection. Angiology 2014;65:274-283.

\section{Subspecialty Alerts by E-mail!}

Customize your online journal experience by signing up for e-mail alerts related to your subspecialty or area of interest. Access this free service by clicking on the "My Alerts" link on the home page. An extensive list of subspecialties, methods, and study design choices will be available for you to choose from-allowing you priority alerts to cutting-edge research in your field!

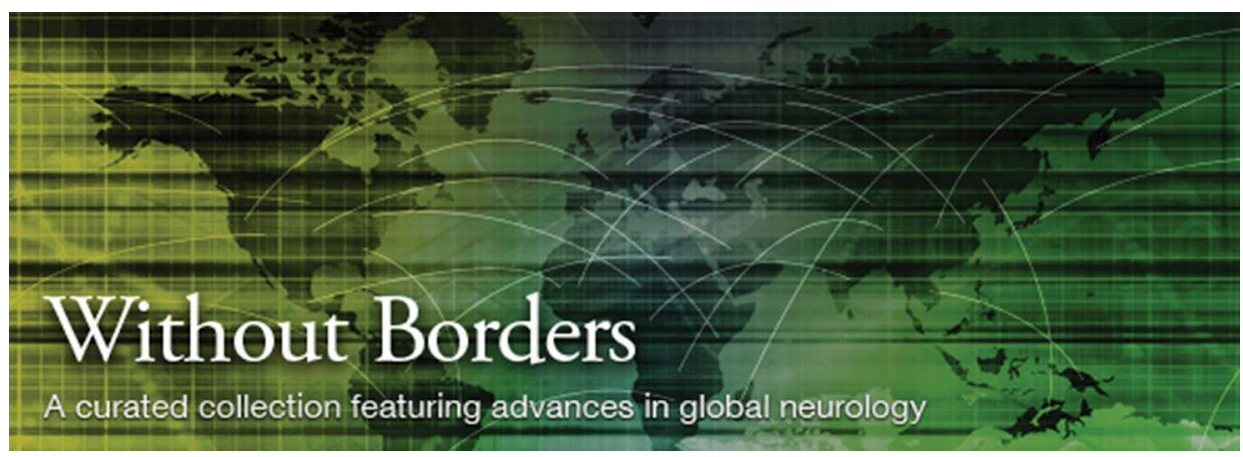

\section{Without Borders - A curated collection featuring advances in global neurology}

This Neurology ${ }^{\circledR}$ special interest website is the go-to source for tracking science and politics of neurology beyond the United States, featuring up-to-the-minute blogs, scholarly perspectives, and academic review of developments and research from Neurology journals and other sources. Curated by Gretchen L. Birbeck, MD, MPH.

Expand your world view at Neurology.org/woborders. 


\section{Neurology}

\section{Clinical Reasoning: Sudden hearing loss with vertigo in a 42-year-old woman}

Jeong-Yoon Choi, Hyo-Jung Kim and Ji-Soo Kim

Neurology 2020;94;1042-1047 Published Online before print May 4, 2020

DOI 10.1212/WNL.0000000000009591

\section{This information is current as of May 4, 2020}

\section{Updated Information \& Services}

\section{References}

Subspecialty Collections

Permissions \& Licensing

Reprints including high resolution figures, can be found at: http://n.neurology.org/content/94/23/1042.full

This article cites 8 articles, 1 of which you can access for free at: http://n.neurology.org/content/94/23/1042.full\#ref-list-1

This article, along with others on similar topics, appears in the following collection(s):

\section{All Neurotology}

http://n.neurology.org/cgi/collection/all_neurotology

Embolism

http://n.neurology.org/cgi/collection/embolism

Other cerebrovascular disease/ Stroke

http://n.neurology.org/cgi/collection/other_cerebrovascular_disease_st roke

Information about reproducing this article in parts (figures,tables) or in its entirety can be found online at:

http://www.neurology.org/about/about_the_journal\#permissions

Information about ordering reprints can be found online:

http://n.neurology.org/subscribers/advertise

Neurology ${ }^{\circledR}$ is the official journal of the American Academy of Neurology. Published continuously since 1951, it is now a weekly with 48 issues per year. Copyright @ 2020 American Academy of Neurology. All rights reserved. Print ISSN: 0028-3878. Online ISSN: 1526-632X.

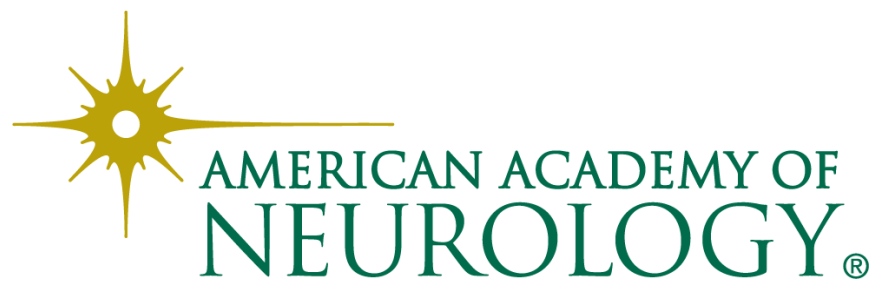

